\title{
Construction and characterization of a novel glucose dehydrogenase-leucine dehydrogenase fusion enzyme for the biosynthesis of L-tert-leucine
}

\author{
Langxing Liao ${ }^{1 \dagger}$, Yonghui Zhang ${ }^{1,2 \dagger}$, Yali Wang ${ }^{1}$, Yousi Fu' ${ }^{1}$, Aihui Zhang ${ }^{1}$, Ruodian Qiu' ${ }^{1}$, Shuhao Yang ${ }^{1}$
} and Baishan Fang ${ }^{1,3^{*}}$ (D)

\begin{abstract}
Background: Biosynthesis of L-tert-leucine (L-tle), a significant pharmaceutical intermediate, by a cofactor regeneration system friendly and efficiently is a worthful goal all the time. The cofactor regeneration system of leucine dehydrogenase $(\mathrm{LeuDH})$ and glucose dehydrogenase $(\mathrm{GDH})$ has showed great coupling catalytic efficiency in the synthesis of L-tle, however the multi-enzyme complex of GDH and LeuDH has never been constructed successfully.

Results: In this work, a novel fusion enzyme (GDH-R3-LeuDH) for the efficient biosynthesis of L-tle was constructed by the fusion of LeuDH and GDH mediated with a rigid peptide linker. Compared with the free enzymes, both the environmental tolerance and thermal stability of GDH-R3-LeuDH had a great improved since the fusion structure. The fusion structure also accelerated the cofactor regeneration rate and maintained the enzyme activity, so the productivity and yield of L-tle by GDH-R3-LeuDH was all enhanced by twofold. Finally, the space-time yield of L-tle catalyzing by GDH-R3-LeuDH whole cells could achieve $2136 \mathrm{~g} / \mathrm{L} /$ day in a $200 \mathrm{~mL}$ scale system under the optimal catalysis conditions ( $\mathrm{pH} 9.0,30^{\circ} \mathrm{C}, 0.4 \mathrm{mM}$ of NAD ${ }^{+}$and $500 \mathrm{mM}$ of a substrate including trimethylpyruvic acid and glucose).
\end{abstract}

Conclusions: It is the first report about the fusion of GDH and LeuDH as the multi-enzyme complex to synthesize L-tle and reach the highest space-time yield up to now. These results demonstrated the great potential of the GDHR3-LeuDH fusion enzyme for the efficient biosynthesis of L-tle.

Keywords: L-tert-leucine, Glucose dehydrogenase, Leucine dehydrogenase, Fusion enzyme, Whole cells

\footnotetext{
*Correspondence: fbs@xmu.edu.cn

${ }^{\dagger}$ Langxing Liao and Yonghui Zhang contributed equally to this work and should be considered co-first authors

${ }^{1}$ Department of Chemical and Biochemical Engineering, College

of Chemistry and Chemical Engineering, Xiamen University, Xiamen 361005, People's Republic of China

Full list of author information is available at the end of the article
}

\section{Background}

Due to the tremendous application in marketed drugs, chemical and enzymatic methods of producing L-tertleucine ( $\mathrm{L}$-tle), which is widely used as a chiral building block in the synthesis of anti-tumor and anti-virus drugs $[1,2]$, such as atazanavir, telaprevir and boceprevir, have been developed rapidly. However, the disadvantages were significant and pervasive existed in most chiral L-tert chemical catalysis producing process, including energy-consuming, environmentally-unfriendly, and low

(c) The Author(s) 2021. This article is licensed under a Creative Commons Attribution 4.0 International License, which permits use, sharing, adaptation, distribution and reproduction in any medium or format, as long as you give appropriate credit to the original author(s) and the source, provide a link to the Creative Commons licence, and indicate if changes were made. The images or other third party material in this article are included in the article's Creative Commons licence, unless indicated otherwise in a credit line to the material. If material is not included in the article's Creative Commons licence and your intended use is not permitted by statutory regulation or exceeds the permitted use, you will need to obtain permission directly from the copyright holder. To view a copy of this licence, visit http://creativeco mmons.org/licenses/by/4.0/. The Creative Commons Public Domain Dedication waiver (http://creativecommons.org/publicdomain/ zero/1.0/) applies to the data made available in this article, unless otherwise stated in a credit line to the data. 
conversion and enantioselectivity $[3,4]$. The greener biocatalysts, such as leucine dehydrogenase [5], branched chain aminotransferase [6], amidases [7], and proteases [8], penicillinyl enzymes [9], lipases [10], have been developed and applied in L-tle enzymatically producing process over the past few decades. Among those biocatalysts, leucine dehydrogenase (LeuDH, EC 1.4.1.9) exhibited an outstanding conversion efficiency and enantioselectivity which became the main method of L-tle synthesis in the market [11].

In the process of LeuDH production of L-tle, NADH as a cofactor is indispensable and expensive, so an efficient cofactor regeneration system was considered as an ideal solution with high catalytic and economic benefits [11]. In previous research, a cofactor regeneration system was built for the regeneration of expensive cofactor NADH $[5,12,13]$, in which amination of trimethylpyruvic acid (TMA) was reductive by LeuDH coupling with Formate dehydrogenase (FDH, EC 1.2.1.2) or Glucose dehydrogenase (GDH, EC 1.1.1.47) to generate NADH. For example, Degussa AG (now Evonik AG) reported a LeuDH and FDH coupling system to perform repeated batch reactions with an enzyme membrane reactor on a ton scale and the space-time yield of L-tle achieved $638 \mathrm{~g} / \mathrm{L} /$ day [14]. LeuDH and GDH were co-expressed in E. coli to constructed whole cells biocatalyst for L-tle production, which obtain space-time yield of $945 \mathrm{~g} / \mathrm{L} /$ day produce in condition of $1.3 \mathrm{~h}$ and $0.5 \mathrm{M}$ substrate concentration [13]. However, the poor structural stability and the high cost of purification and immobilization of free enzyme system limit the industrial application.

Inspired by sophisticated protein complexes in nature $[15,16]$, artificial multi-enzyme systems have been reported to improve structural stability, promote the cofactor regeneration efficiency and reduce the cost of free enzyme system $[17,18]$. LeuDH and FDH with PDZ (PSD95/Dlg1/Zo-1) domain and the corresponding ligand of the metazoan (PDZlig) were fused and assembled as multiple supramolecules to improve the $\operatorname{NAD}(\mathrm{H})$ recycling efficiency and structural stability [19]. A series of engineering bifunctional enzyme complex fusing LeuDH and FDH with different peptide linkers were built [20], which could accelerate the transfer of cofactors to increase catalytic rate and stabilize enzyme structure. The multi-enzyme complexes of FDH and LeuDH has been extensively studied, however the low enzyme activity of FDH in the coupling system limited the overall catalytic efficiency [21]. To the best of our knowledge, the GDH may exhibit great potential in the cofactor regeneration of NADH [22], while has not been reported for the construction with LeuDH to form the multi-enzyme complexes in the biosynthesis of $\mathrm{L}$-tle.
There were some bifunctional enzymes can individually catalyze cascade reactions. For example, the chlamydial DapF had function of both racemase and epimerase [23]. Through gene fusion, an engineering bifunctional enzyme could be constructed with two functions and able to catalyze coupling reaction. In this paper, we constructed a bifunctional fusion enzyme, in which LeuDH and GDH played the roles of producing L-tle and cofactor regeneration respectively (Scheme 1). After purification, the properties of novel fusion enzyme, which was expressed in E. coli were tested and compared with that of free enzyme. The obtained GDH-R3-LeuDH fusion enzyme had shown improved catalytic efficiency and stability in L-tle production which make it a candidate for further industry utilities.

\section{Results}

The construction of fusion enzyme and free enzymes The GDH (PDB ID: 1GCO) is a tetramer and the LeuDH (PDB ID: 1LEH) is an octamer in our study (Fig. 1a, b), meaning that the integrity of oligomeric structure is an important factor for maintaining enzyme activity in the process of fusion [24]. Through the oligomeric structures of GDH and LeuDH, we found that the $\mathrm{N}$-terminus of GDH participates in the formation of GDH tetramers, while the C-terminus of LeuDH participates in the formation of LeuDH octamer (Fig. 1c, d). The PDB analysis showed that the fusion sequence from GDH to LeuDH would be benefit for the integrality of both enzyme structures. After determining the order of fusion, the fusion gene of GDH and LeuDH was inserted into a sequence of rigid peptide linker (EAAAK) 3 through OE-PCR (Overlap Extension Polymerase Chain Reaction). Finally, the fusion enzyme (GDH-R3-LeuDH), GDH and LeuDH were all expressed in recombinant $E$. coli successfully and obtained the pure enzymes through purification of HisTrap column (Fig. 2).

\section{The enzymatic properties of fusion enzyme and free enzymes}

After obtaining the fusion enzyme, comparing the enzymatic properties of the fusion enzyme and the free enzyme could evaluate the effect of the fusion. The activities of fusion enzyme (GDH-R3-LeuDH), GDH and LeuDH were determined in various $\mathrm{pH}$ values. Reducing the activity of fusion GDH was observed higher than $80 \%$ in a $\mathrm{pH}$ range of around $6.0-9.0$, while that of free GDH only retained $27.4 \%$ at $\mathrm{pH} 6.0$ and $51.5 \%$ at $\mathrm{pH} 9.0$ (Fig. 3a). The highest oxidizing activity of fusion and free LeuDH were all observed at $\mathrm{pH} 10.0$, while the activity of fusion and free LeuDH only left $35.8 \%$ and $20.2 \%$ at $\mathrm{pH}$ 8.0, respectively (Fig. $3 \mathrm{~b}$ ). This result indicated that the 


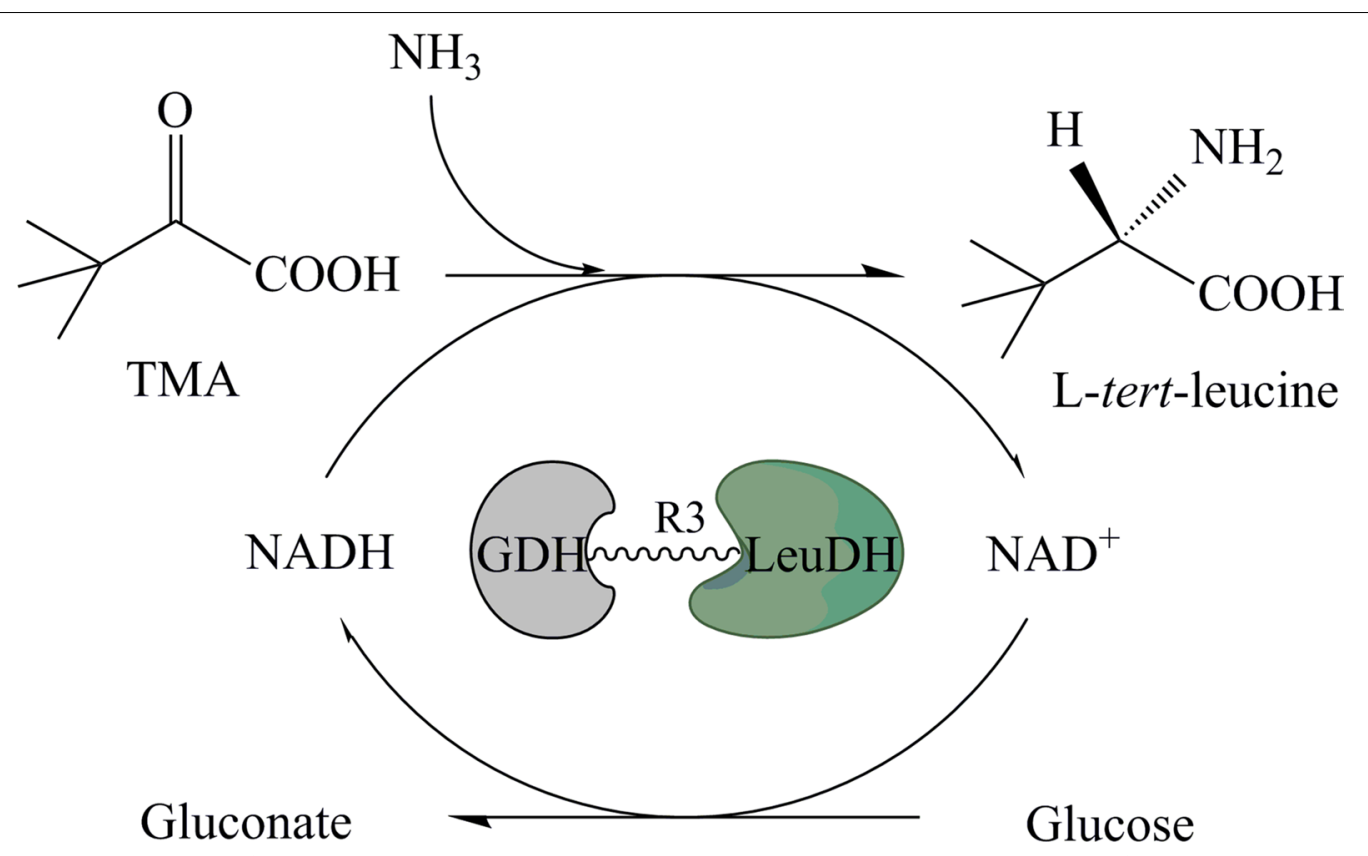

Scheme 1 Reductive amination of trimethylpyruvic acid using GDH-LeuDH fusion enzyme for the biosynthesis of optically pure L-tert-leucine
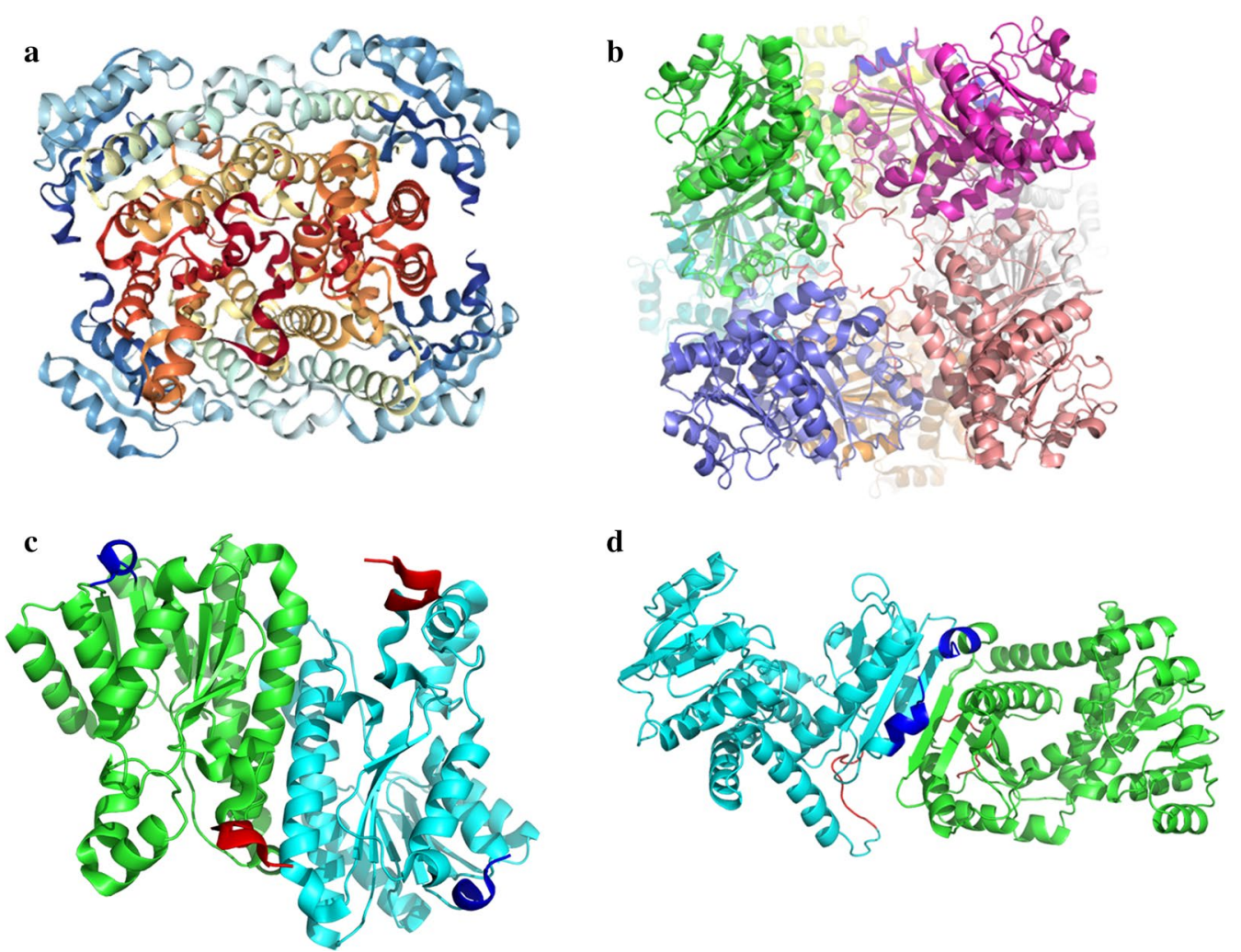

Fig. 1 The PDB structures of GDH and LeuDH. a GDH from Bacillus megaterium (PDB ID: 1GCO, sequence identity: 96.69); $\boldsymbol{b}$ LeuDH from Bacillus sphaericus (PDB ID: 1LEH, sequence identity: 76.92); $\mathbf{c}$ the N/C-terminus of $\mathrm{GDH}$; $\mathbf{d}$ the N/C-terminus of LeuDH; $\mathrm{N}$-terminus (blue), indicates C-terminus (red) 
$\mathbf{a}$

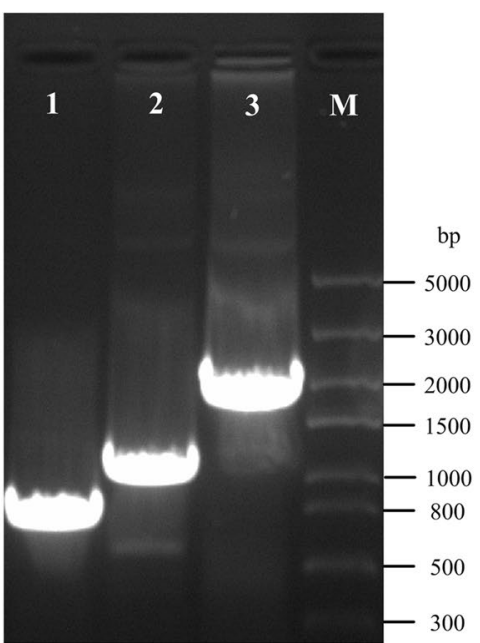

b

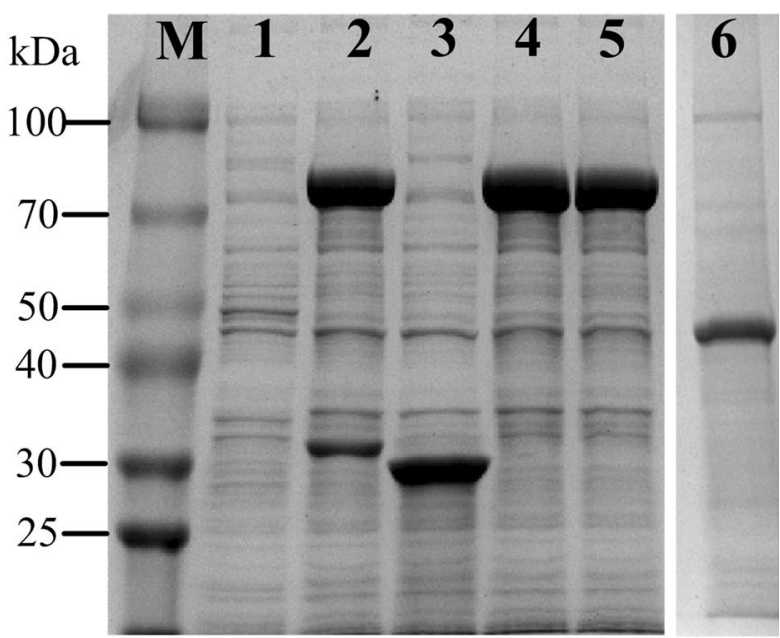

Fig. 2 The structure of recombinant E. coli. a Electrophoresis of PCR products and overlap PCR products of gdh and leudh (Lane: M, DNA marker; Lanes: 1, gdh; 2, leudh; 3, GDH-R3-LeuDH). b SDS-PAGE analysis of cell-free crude extracts of IPTG-induced recombinant E. coli (Lane: M, molecular weight marker; lane 1, control group; lane: 2, 4, 5, expression of GDH-R3-LeuDH fusion enzyme; lane: 3, expression of GDH; lane: 6, expression of LeuDH)
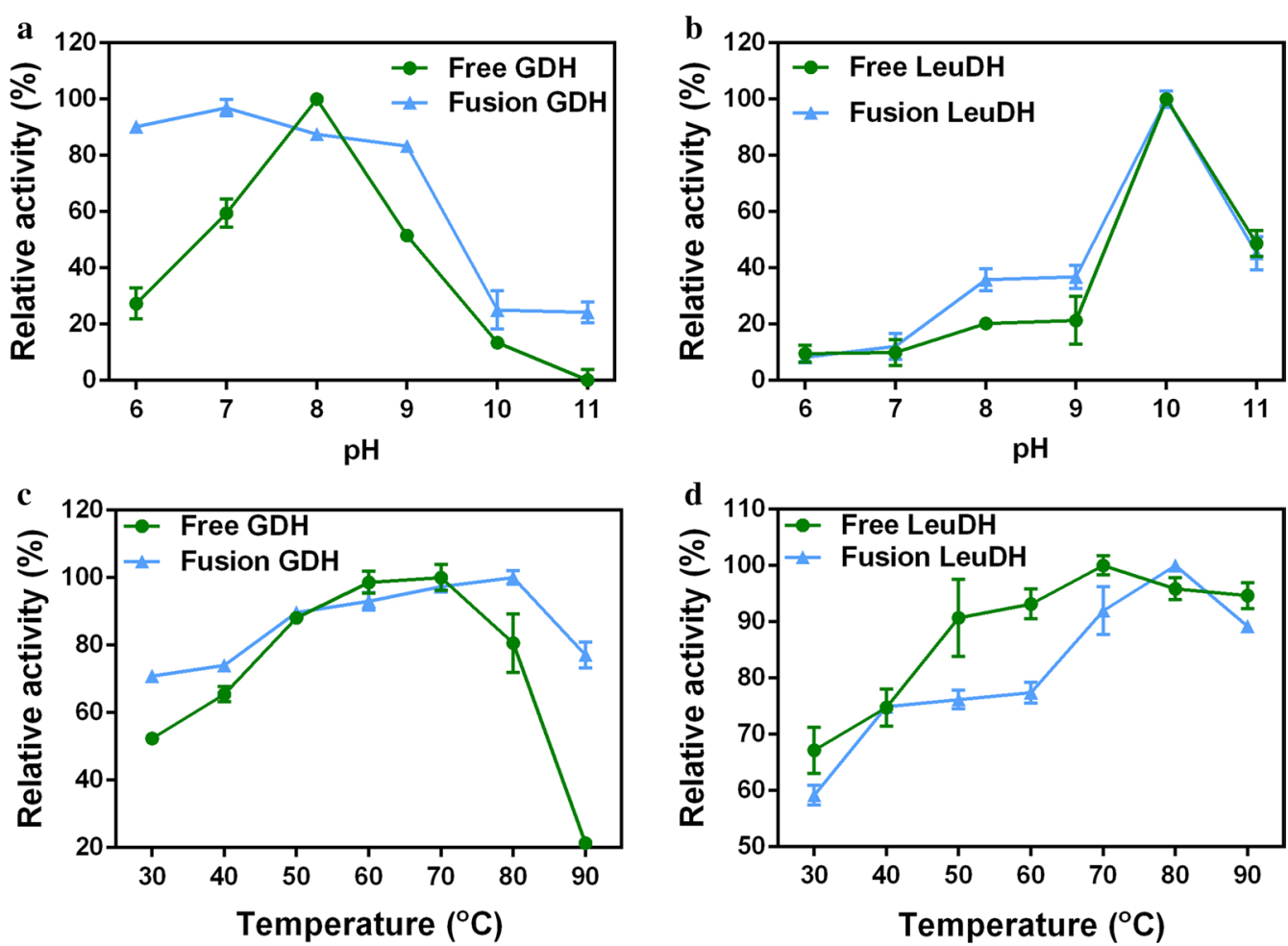

Fig. 3 Effects of $\mathrm{pH}$ and temperature on enzyme activities. a Effects of $\mathrm{pH}$ on $\mathrm{GDH} ; \mathbf{b}$ Effects of $\mathrm{pH}$ on LeuDH; $\mathbf{c}$ Effects of temperature on $\mathrm{GDH}$; $\mathbf{d}$ Effects of temperature on LeuDH. Enzyme assays were performed in $0.8 \mathrm{M} \mathrm{NH}_{4} \mathrm{Cl}-\mathrm{NH}_{3} \cdot \mathrm{H}_{2} \mathrm{O}$ buffers or PBS buffers of different pH at $30{ }^{\circ} \mathrm{C}$, using TMA and $\mathrm{NADH}$ as substrates (for LeuDH) or glucose and NAD+ as substrates (for $\mathrm{GDH}$ ). Enzyme assays were performed in $0.8 \mathrm{M} \mathrm{NH}_{4} \mathrm{Cl}-\mathrm{NH}_{3} \cdot \mathrm{H}_{2} \mathrm{O}$ buffers ( $\mathrm{pH}$ 10.0) or PBS buffers ( $\mathrm{pH}$ 7.4) of at different temperatures, using TMA and NADH as substrates (for LeuDH) or glucose and NAD ${ }^{+}$as substrates (for $\mathrm{GDH}$ ). Free enzyme (circles), fusion enzyme (triangles). Data represent the mean \pm standard deviation of triplicate samples. Relative activity was based on a percentage of maximum activity under the experimental conditions 
fusion enzyme had better $\mathrm{pH}$ adaptability compared with free enzymes.

The effect of temperature on the GDH-R3-LeuDH, $\mathrm{GDH}$ and $\mathrm{LeuDH}$ were examined in the temperatures range from 30 to $90{ }^{\circ} \mathrm{C}$. The optimal temperature for $\mathrm{GDH}$ and LeuDH of fusion enzyme were both $80{ }^{\circ} \mathrm{C}$, while free GDH and LeuDH were both $70{ }^{\circ} \mathrm{C}$ (Fig. 3c, d). Additionally, GDH of fusion enzyme retained more than $70 \%$ of the highest activity at the temperatures ranged from 30 to $90{ }^{\circ} \mathrm{C}$, while free $\mathrm{GDH}$ only retained $52.4 \%$ at $30{ }^{\circ} \mathrm{C}$ and $21.4 \%$ at $90{ }^{\circ} \mathrm{C}$ (Fig. 3c). The results demonstrated that the fusion enzyme might be applied for biosynthesis reactions at a higher temperature.

The residual activities of the fusion enzyme and free enzymes were determined after incubating at 40,50 and $60{ }^{\circ} \mathrm{C}$ for $1 \mathrm{~h}$. As shown in Fig. 4, the residual activity decreased with temperature increasing. Free GDH was almost inactivated at a temperature higher than $50{ }^{\circ} \mathrm{C}$, while fusion $\mathrm{GDH}$ retained $60 \%$ and $20 \%$ activity at 50 and $60{ }^{\circ} \mathrm{C}$, respectively (Fig. 4a). Fusion LeuDH maintained higher enzyme activity than free LeuDH in different incubating temperatures (Fig. 4b). The fusion enzyme exhibited significant thermal stability both in GDH and LeuDH moieties compared with free GDH and LeuDH, indicating that the fusion enzyme was beneficial for stabilizing fused moieties. The improved environmental adaptability and thermal stability of the fusion enzyme would have a positive impact on the catalytic performance of the coupling system.

\section{The catalytic performance of fusion enzyme and free enzyme system}

To study the catalytic performance of different multienzyme coupling systems, the synthesis of L-tle was implemented with two sets of biocatalysts, fusion enzyme and free enzyme system. The concentrations of synthesis of L-tle were determined by the standard curve of L-tertleucine by HPLC (Additional file 1: Fig. S1). The productivity of L-tle synthesized by fusion enzyme in $1 \mathrm{~h}$ was about $200 \%$ as much as that of the free enzyme system, indicating fusion enzyme had a higher initial catalytic rate. After $24 \mathrm{~h}$, the yield of L-tle synthesized by fusion enzyme could achieve about $90 \%$ while the free enzyme system was only about $40 \%$, meaning the catalytic efficiency of the fusion enzyme was better than that of the free enzyme system (Fig. 5). The advantages of fusion enzymes were reflected in the catalytic rate and yield compared with free enzyme system.

\section{The biosynthesis of L-tle by fusion enzyme}

To obtain the optimal reaction conditions for the biosynthesis of L-tle, the effect of reaction conditions on the catalytic efficiency was investigated. Considering the investigation of the optimal $\mathrm{pH}$ and temperature and thermal stability of the fusion enzyme, the most suitable catalytic of $\mathrm{pH}$ and temperature might be between $8.0-10.0$ and $30-50{ }^{\circ} \mathrm{C}$, respectively. The whole cells were used to synthesize L-tle in all experiments in this part. The results showed that the catalytic efficiency at $\mathrm{pH}$ 9.0 and 10.0 was significantly higher than that at $\mathrm{pH} 8.0$ for the low activity of LeuDH moieties of fusion enzyme at $\mathrm{pH} 8.0$ (Fig. 6a). The reaction rate and yield were extremely low at $50{ }^{\circ} \mathrm{C}$ (less than $10 \%$ ) for the whole cells might inactivate rapidly under the reaction condition (Fig. 6b). The productivity of L-tle at $40{ }^{\circ} \mathrm{C}$ was higher than that at $30{ }^{\circ} \mathrm{C}$ in a short time $(1 \mathrm{~h})$, but the final yield of L-tle was still below $30{ }^{\circ} \mathrm{C}$. Finally, pH 9.0 and $30{ }^{\circ} \mathrm{C}$ were the preferred reaction conditions.
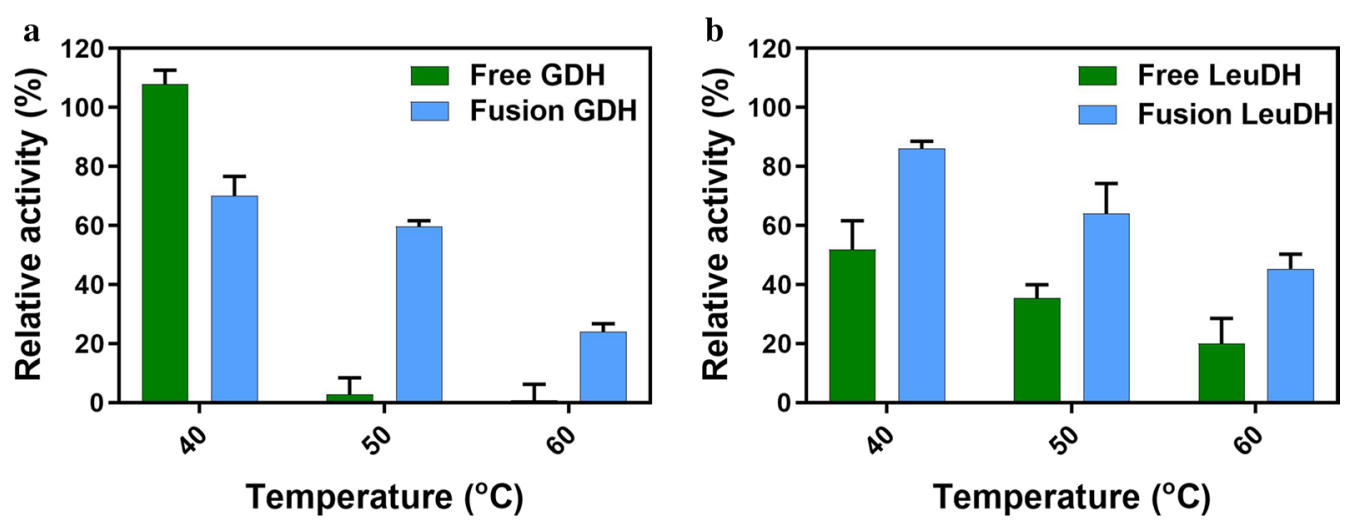

Fig. 4 Thermal stability of enzymes. a Free GDH and fusion GDH; b Free LeuDH and fusion LeuDH. Enzyme assays were performed in $0.8 \mathrm{M}$ $\mathrm{NH}_{4} \mathrm{Cl}-\mathrm{NH}_{3} \cdot \mathrm{H}_{2} \mathrm{O}$ buffers ( $\mathrm{pH}$ 10.0) or PBS buffers ( $\mathrm{pH}$ 7.4) of at different pre-incubated temperatures for $1 \mathrm{~h}$, using TMA and NADH as substrates (for LeuDH) or glucose and NAD+ as substrates (for GDH). Free enzyme (circles), fusion enzyme (triangles). Data represent the mean \pm standard deviation of triplicate samples. Relative activity was based on enzyme activity before treatment as one hundred percent 


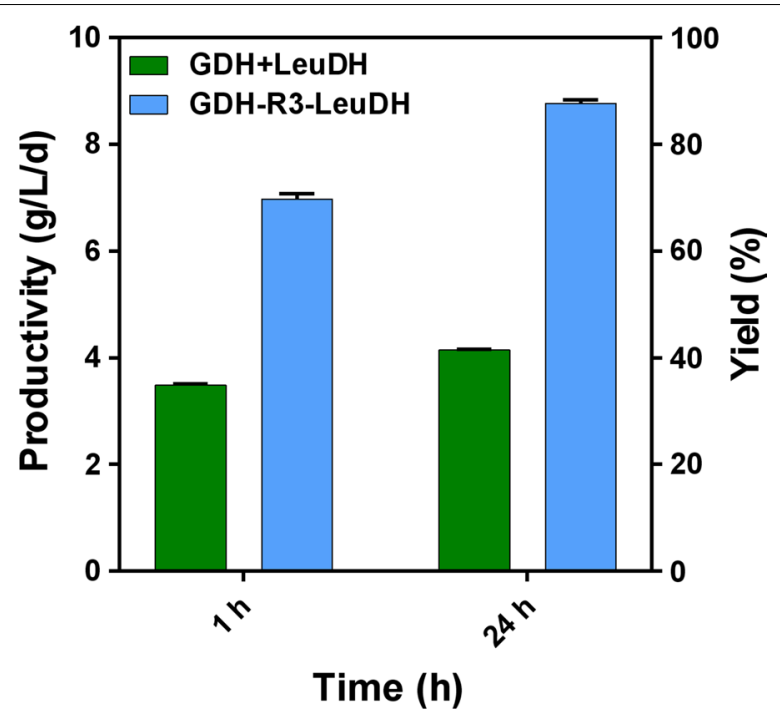

Fig. 5 The synthesis of L-tle catalyzed by fusion enzyme or free enzyme system. The enzyme activities were kept as equal for both reaction systems. Reaction conditions: fusion enzyme or free enzyme system, $100 \mathrm{mM}$ substrate, $0.4 \mathrm{mM} \mathrm{NAD}{ }^{+}, 30^{\circ} \mathrm{C}$, pH 9.0, $200 \mathrm{rpm}$. Yield means the ratio of the synthesized L-tle actually to the synthesized L-tle theoretically. Data represent the mean \pm standard deviation of duplicate samples. Free enzyme system (green), fusion enzyme (blue)

The effects of different kinds and concentrations of cofactor on the catalytic reaction were investigated. Regardless of adding $\mathrm{NADH}$ or $\mathrm{NAD}^{+}$, the catalytic rate and yield of fusion enzyme were equivalent, while the fusion enzyme showed scarcely any catalytic efficiency without the addition of cofactor (Fig. 6c). With the increase of $\mathrm{NAD}^{+}$concentration, the productivity increased linearly firstly and became equilibrating after reaching $0.4 \mathrm{mM}$, which indicating that the concentration of $\mathrm{NAD}^{+}$was saturated (Fig. 6d).

Judging from the synthesis of L-tle, the substrate concentration promoted the initial catalytic rate and concentration of L-tle synthesized by fusion enzyme, while the yield of L-tle decreased for the limit of the substrate (Fig. 6 e, Additional file 1: Fig. S2). The productivity of L-tle increased with the increase of the concentration of fusion enzyme, which indicating that the increase in the concentration of fusion enzyme could improve the catalytic efficiency (Fig. 6f). Finally, the substrate catalyzed by fusion enzyme with high activities finished in $1 \mathrm{~h}$ at the low concentration and in $4 \mathrm{~h}$ at the higher concentration, showing the high content of whole cells had a better catalytic rate (Fig. 7a).

Taking comprehensive consideration of reaction conditions and the effect of substrate concentration, to achieve the application of synthesis of L-tle catalyzed by fusion enzyme, the catalytic reaction was scaled up with the high content of whole cells under a single batch of catalytic experiments. A $200 \mathrm{~mL}$ scale system containing $40 \mathrm{~g} / \mathrm{L}$ of whole cells, $500 \mathrm{mM}$ substrate and $0.4 \mathrm{mM}$ $\mathrm{NAD}^{+}$under $30^{\circ} \mathrm{C}, 200 \mathrm{rpm}$ and $\mathrm{pH} 9.0$ was built. The yield of L-tle was $67.9 \%$ after half an hour of reaction while reached the highest value $(74.7 \%)$ in $2 \mathrm{~h}$, indicating the synthesis reaction of L-tle catalyzed by fusion enzyme basically completed after half an hour (Fig. 7b). The concentration and space-time yield of L-tle achieved $44.5 \mathrm{~g} / \mathrm{L}$ and $2136 \mathrm{~g} / \mathrm{L} /$ day respectively. All the e.e. values of $\mathrm{L}$-tle were more than $99 \%$.

\section{Discussion}

In order to ensure that the synthetic process catalyzed by oxidoreductase who need the expensive cofactor $\mathrm{NAD}(\mathrm{H})$ is economically feasible, an efficient cofactor regeneration system is the choice. The cofactor regeneration systems are usually constructed by two catalytic entities, and the multi-enzyme complex could shorten the spatial distance of catalytic entities to accelerate the regeneration of cofactors $[25,26]$. Fusion enzyme is an effective method to realize the construction of multienzyme complex, while how to maintain the enzyme activities of two enzyme is the most difficult problem. Firstly, by analyzing the PDB structure, we determined the sequence fusion sequence from GDH to LeuDH, so that the integrity of the oligomerization interface of each oligomerase could be maintained. Then, in order to prevent the two enzymes from interacting with each other during the folding process, it is essential to add a peptide link to mediate $[18,27]$.

The peptide linkers, mainly includes flexible peptide and rigid peptide, were used to build fusion proteins in many studies. A fusion protein MBP-(EAAAK)3-GFP(GGGGS)3-HepA was constructed by (GGGGS)3 and (EAAAK) 3 to obtain a complex with good activity and thermal stability [28]. In order to maintain the two molecules in a reasonable distance, a (EAAAK) 3 was used to fuse the $\beta$-glucanase (Glu) and xylanase (Xyl) double enzymes and got a Glu-xyl fusion enzyme including the dual enzyme activities [27]. The sequence (EAAAK) 3 could form $\alpha$ helix and provide a rigid peptide linker to keep the oligomers of fusion enzyme in the proper distance with good behavior and improve the structural stability. Therefore, the fusion enzyme fused the sequence from GDH to LeuDH mediated by (EAAAK)3. Finally, the activities of GDH and LeuDH in fusion enzyme were $0.80 \mathrm{U} / \mathrm{mg}$ and $0.99 \mathrm{U} / \mathrm{mg}$ respectively. The results indicated that fusion enzyme mediated by a rigid linker with the right fusion sequence could keep the enzyme activities and reduce the difference of activities between GDH and LeuDH to enhance the efficiency of the coupling system. 

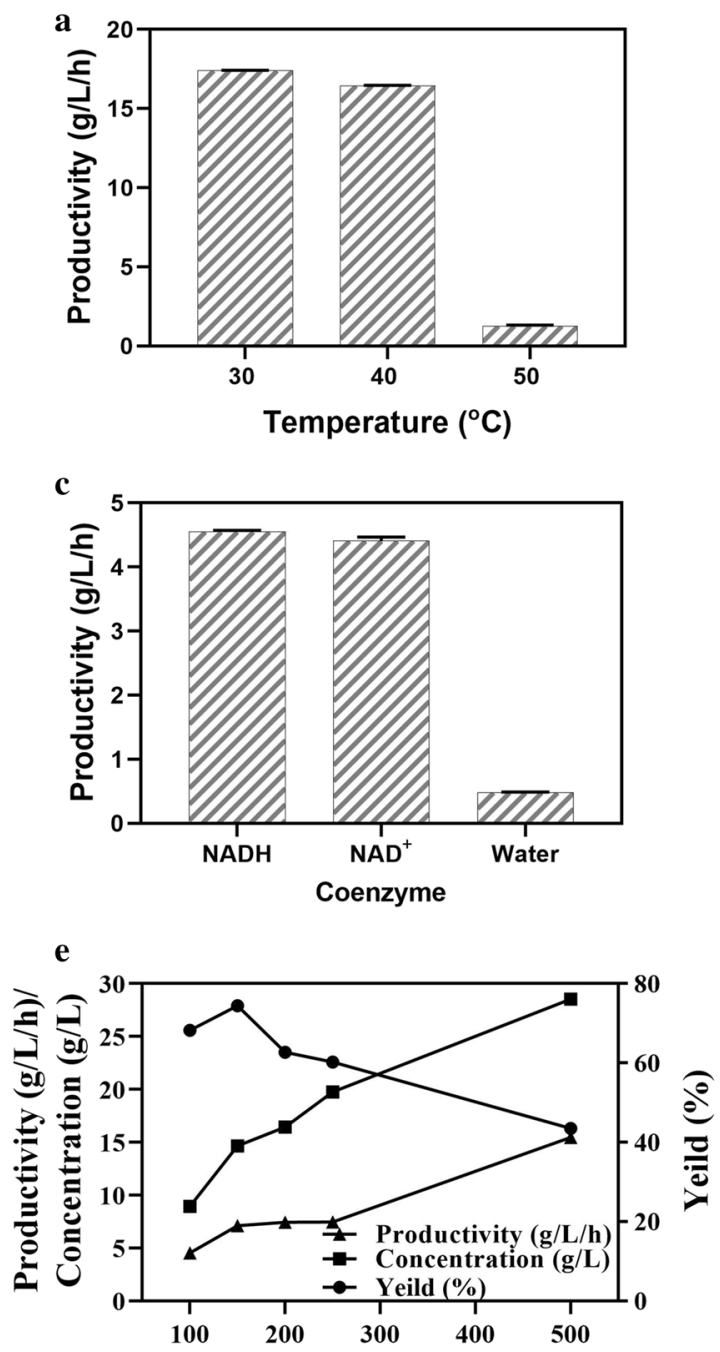

Substrate Concentration $(\mathrm{mM})$

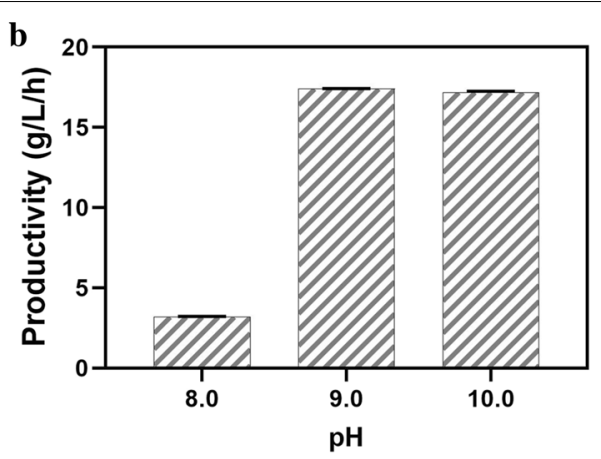

d

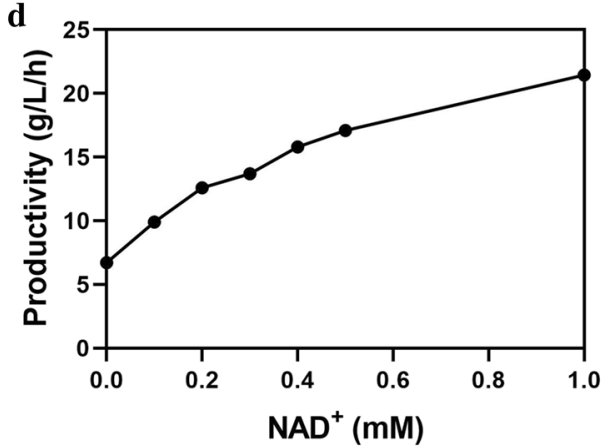

f

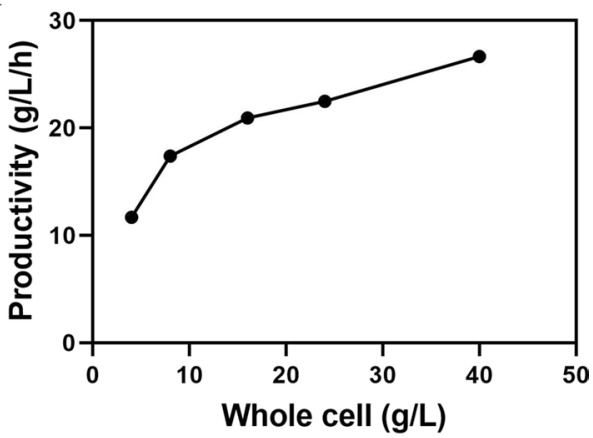

Fig. 6 The synthesis of L-tle catalyzed by fusion enzyme whole cells. a $2 \mathrm{~mL}$ reaction system including $8 \mathrm{~g} / \mathrm{L}$ whole cells, $500 \mathrm{mM}$ substrate and $0.4 \mathrm{mM} \mathrm{NAD}{ }^{+}$under $30 / 40 / 50{ }^{\circ} \mathrm{C}, \mathrm{pH}$ 9.0, $200 \mathrm{rpm}$. b $2 \mathrm{~mL}$ reaction system including $8 \mathrm{~g} / \mathrm{L}$ whole cells, $500 \mathrm{mM}$ substrate and $0.4 \mathrm{mM}$ NAD ${ }^{+}$under $30{ }^{\circ} \mathrm{C}, \mathrm{pH}$ 8.0/9.0/10.0, $200 \mathrm{rpm} . \mathbf{c} 2 \mathrm{~mL}$ reaction system including $8 \mathrm{~g} / \mathrm{L}$ whole cells, $100 \mathrm{mM}$ substrate and different kinds of cofactor under $30{ }^{\circ} \mathrm{C}$, $\mathrm{pH}$ 9.0, $200 \mathrm{rpm}$. $\mathbf{d} 2 \mathrm{~mL}$ reaction system including $8 \mathrm{~g} / \mathrm{L}$ whole cells, $500 \mathrm{mM}$ substrate and different concentrations of $\mathrm{NAD}^{+}$under $30^{\circ} \mathrm{C}$, $\mathrm{pH} 9.0$, $200 \mathrm{rpm}$. e $2 \mathrm{~mL}$ reaction system including $8 \mathrm{~g} / \mathrm{L}$ whole cells, different concentrations of substrate and $0.4 \mathrm{mM} \mathrm{NAD}+$ under $30{ }^{\circ} \mathrm{C}, \mathrm{pH} 9.0,200 \mathrm{rpm}$. Productivity (triangles), concentration (squares), yield (circles). (f) $2 \mathrm{~mL}$ reaction system including different concentrations of whole cells, $500 \mathrm{mM}$ substrate and $0.4 \mathrm{mM} \mathrm{NAD}^{+}$under $30{ }^{\circ} \mathrm{C}, \mathrm{pH} 9.0,200 \mathrm{rpm}$. Productivity indicates the concentration of L-tle synthesized in $1 \mathrm{~h}$. Data represent the mean \pm standard deviation of duplicate samples

For the enzyme-catalyzed reaction process, maintaining the stability of the enzyme activities is essential for the catalytic efficiency. Fusion enzyme could make the protein structure of multi-enzyme more stable performancing in the adaptability of enzymes including $\mathrm{pH}$ and temperature [29], which exhibited significant enzyme activities in a wide range of $\mathrm{pH}$ and temperature and excellent thermal stability in our study (Figs. 3, 4). It had been reported that the fusion of two multimeric enzymes could lead to the formation of a multimeric protein network [30] and the engineered bifunctional fusion proteins compose of two multimeric enzymes could form oligomers [31]. In this work, LeuDH and GDH usually form in octamer and tetramer respectively, then the implementation of GDH-R3-LeuDH could form a multimeric state which explained the enhance of stability of the fusion enzyme. It meant the catalytic reaction of GDH-R3-LeuDH could maintain last longer and reduce 

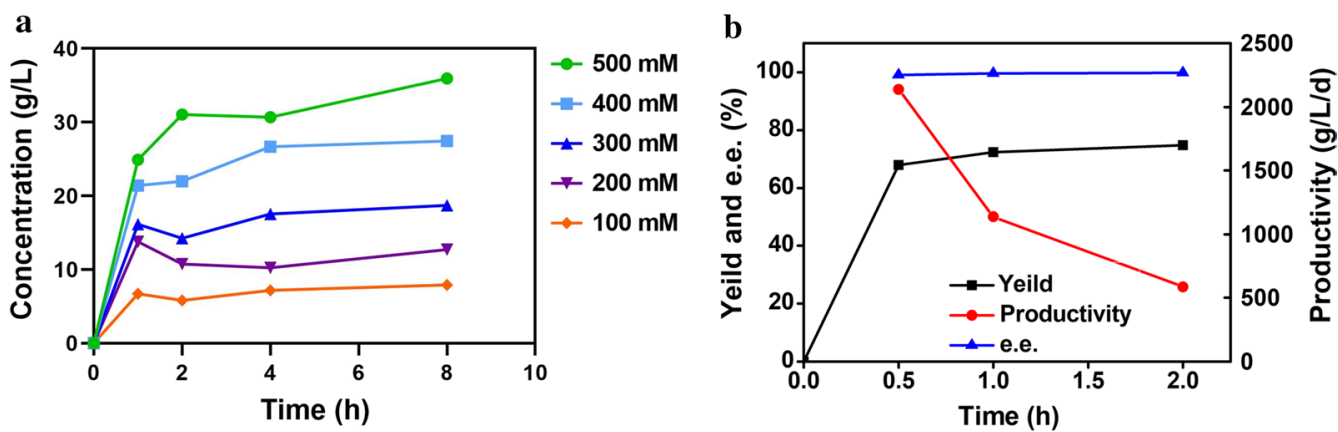

Fig. 7 The synthesis of L-tle catalyzed by high content of fusion enzyme whole cells. a $2 \mathrm{~mL}$ reaction system including $40 \mathrm{~g} / \mathrm{L}$ whole cells, different concentrations of substrate and $0.4 \mathrm{mM} \mathrm{NAD}+$ under $30^{\circ} \mathrm{C}, \mathrm{pH}$ 9.0, $200 \mathrm{rpm} .500 \mathrm{mM}$ (green), $400 \mathrm{mM}$ (wathet), $300 \mathrm{mM}$ (blue), $200 \mathrm{mM}$ (purple), $100 \mathrm{mM}$ (orange). b $200 \mathrm{~mL}$ reaction system including $40 \mathrm{~g} / \mathrm{L}$ whole cells, $500 \mathrm{mM}$ substrate and $0.4 \mathrm{mM} \mathrm{NAD}^{+}$under $30^{\circ} \mathrm{C}, \mathrm{pH} 9.0,200 \mathrm{rpm}$. Yield (squares), productivity (circles), e.e. (triangles). Data represent the mean \pm standard deviation of duplicate samples

the regulation of the reaction system profit from the improvement of environmental tolerance and thermal stability.

The fusion structure not only gave the multi-enzyme complex excellent stability, but also shortened the spatial distance between the two enzymes. As we all known, the substrate channeling effect was a mechanism about intermediates delivery in multi-enzyme complexes [32], and it allowed the direct transfer of intermediate from one enzyme to an adjacent enzyme and decreased the diffusion of intermediate into solution $[18,33]$. The productivity of L-tle synthesized by GDH-R3-LeuDH was twofold of free enzyme system, which indicated the acceleration of fusion enzyme in the catalytic reaction of L-tle synthesis (Fig. 5). The fusion structure bridged the doubleenzyme to form substrate channeling effect and make the transfer of cofactor quicker. Compared with free enzyme system, the higher final yield of L-tle synthesized by GDH-R3-LeuDH illustrated the fusion enzyme could maintain the operation of coupling system and enhance the efficiency of the L-tle synthesis.

To establish the catalytic system of GDH-R3-LeuDH whole cells, the effects of reaction conditions, cofactor, and the concentration of substrate on L-tle synthesized by whole cells were investigated separately (Fig. 6). The optimum conditions for the catalytic system were: $\mathrm{pH}$ 9.0, $30{ }^{\circ} \mathrm{C}, 0.4 \mathrm{mM}\left(\mathrm{NAD}^{+}\right)$and $500 \mathrm{mM}$ (substrate). Although the structure of GDH-R3-LeuDH was stable, the optimum reaction conditions on the catalytic system were still mild and tallylied with natural enzymatic reaction [34]. The great environmental tolerance and thermal stability indicated that the fusion enzyme system could realize the synthesis of $\mathrm{L}$-tle without controlling the temperature and $\mathrm{pH}$ in the catalytic process. The low concentration of $\mathrm{NAD}^{+}$could maintain the catalytic reaction of the coupled system, indicating the NADH regeneration by GDH suited for the catalytic efficiency of LeuDH and reduced the cost of cofactor. The results showed that the increasing of substrate concentration would influence the initial catalytic rate and yield of L-tle synthesized by GDH-R3-LeuDH (Fig. 6e), for the substrate concentration is an important parameter in enzymatic reactions and it could influence the full utilization of enzyme activity or result in substrate inhibition $[4,35]$.

The substrate inhibition has always been a major problem that plagued the scale-up in industries [35]. In our study, the productivity of L-tle increased with increasing the content of whole cells (Fig. $6 \mathrm{f}$ ), meaning that increasing the activities of GDH-R3-LeuDH may be a useful strategy to weaken the substrate inhibition. After using the high content of whole cells $(40 \mathrm{~g} / \mathrm{L})$ to catalyze high concentration substrate, the L-tle was synthesized in a short time (Fig. 7 a), which indicating the strategy would increase the catalytic rate of $\mathrm{L}$-tle in the high concentration substrate and reduce reaction time to save costs. So, in order to scale up the catalytic reaction better, the high content of whole cells $(40 \mathrm{~g} / \mathrm{L})$ were used as the catalyst concentration to realize the maximization of L-tle production efficiency.

According to the report on the biosynthesis of L-tle by multi-enzyme coupling system, a LeuDH and FDH free coupling system established by Degussa AG achieved the L-tle space-time yield of $638 \mathrm{~g} / \mathrm{L} /$ day [14], while the LeuDH-FDH enzyme complex (RSLF) could only obtain L-tle with the space-time yield of $57 \mathrm{~g} / \mathrm{L} /$ day in $24 \mathrm{~h}$ [36]. A BcLeuDH/FDH whole cell-catalyst was used to achieve the space-time yield of $109 \mathrm{~g} / \mathrm{L} /$ day [12] and the co-expressed EsLeuDH and BmGDH whole cells could obtain L-tle with the space-time yield of $945 \mathrm{~g} / \mathrm{L} / \mathrm{day}$ in $1.3 \mathrm{~h} \mathrm{[13].} \mathrm{Compared} \mathrm{with} \mathrm{those} \mathrm{reported} \mathrm{cofactor} \mathrm{regen-}$ eration systems, whether the enzyme coupling system or whole-cell system, this work could achieve the L-tle 
space-time yield of $2136 \mathrm{~g} / \mathrm{L} /$ day in a short time which is the highest reported currently (Fig. 7b). The catalytic efficiency of L-tle by fusion enzyme whole cells is conducive to optimize catalytic reaction and industrialization.

\section{Conclusions}

In our study, we applied a rigid peptide linker to construct a bifunctional fusion enzyme containing GDH and LeuDH moieties and compared the properties of the fusion enzyme with that of the free enzymes, including structural properties, enzyme activities, thermal stability and ability of synthesis of L-tle. The new fusion enzyme system (GDH-R3-LeuDH) can stabilize the structure of the dual enzyme, improve the adaptability and stability of the coupling system, keep the dual enzyme close enough to obtain excellent proximity effects, increase the cofactor regeneration efficiency and obtain a good catalytic efficiency of synthesis of L-tle. Finally, the space-time yield of L-tle by GDH-R3-LeuDH whole cells attained $2136 \mathrm{~g} / \mathrm{L} /$ day which is the highest in current research. The GDH-R3-LeuDH fusion enzyme with cofactor regeneration has the potential application for the enzymatic production of L-tle in food and pharmaceutical industries.

\section{Materials and methods Materials}

Primer STAR Max DNA Polymerase, restriction enzymes, ligation enzyme were purchased from Takara (Shiga, Japan). pET-28a (+) expression vector was provided from Novagen. Plasmid, gel extraction, and PCR purification kits were provided from Omega biotek(USA). E. coli BL21 (DE3) competent cell, Isopropyl$\beta$-D-thiogalactopyranoside (IPTG), kanamycin and SDS-PAGE kit were purchased by Transgen (Beijing, China). Modified Bradford Protein Assay Kit, LB broth, D-glucose, NADH and NAD ${ }^{+}$were purchased by Sangon biotech (Shanghai, China). Trimethylpyruvic acid, L-tertleucine and D-tert-leucine were bought from SigmaAldrich (USA).

\section{Gene synthesis}

Using E. coli as the expression host, the amino acid sequence of LeuDH from Bacillus cereus (Sequence ID: WP_000171362.1) was optimized, and then synthesized by Sangon Biotech (Shanghai, China). Using E. coli as the expression host, the amino acid sequence of GDH from Bacillus megaterium (Sequence ID: WP_033578120.1) was optimized, and then synthesized by Sangon Biotech (Shanghai, China).

\section{PDB structure analysis}

The Swiss Model automated comparative protein modeling server [37] (http://swissmodel.expas). According to the amino acid sequence homology, LeuDH from Bacillus sphaericus (PDB ID: 1LEH) and GDH from Bacillus megaterium (PDB ID: 1GCO) were regarded as structural templates. The molecular graphics software program PyMOL (http://www.pymol.org/) was used for explaining the structure of the enzyme.

\section{Gene construction}

OE-PCR (Overlap Extension Polymerase Chain Reaction) was used to construct a sequential chimeric gene encoding LeuDH and GDH mediated by a rigid peptide linker. The oligonucleotides sequences encoding the corresponding amino acid sequences and rigid peptide linkers were shown in Additional file 1: Table S1. The construction of GDH-R3-LeuDH (R3 indicated three units of rigid peptide linker, (EAAAK)3) chimeric gene was taken the cloning process. First, the GDH gene from pUC-GDH was amplified using Fusion-P1 (5'-GGAATT CCATATGTACAAAGATCTGGAAGGTAAAGTTGT$\left.3^{\prime}\right)$ with NdeI restriction site (underlined) and FusionP2 (5'-GATTTCCAATGTCATTTTAGCAGCAGCTTC TTTAGCAGCAGCTTCTTTAGCAGCAGCTTCGCC ACGGCCCGCCTG-3') with sequences that encoding one repeat of rigid peptide linker (R3, underlined). Second, the LeuDH gene from pUC-LeuDH was amplified using Fusion-P3 (5'-ATGACATTGGAAATCTTCGAA TAT- ${ }^{\prime}$ ) and Fusion-P4 (CCGCTCGAGTTACCGGCG ACTAATGATGT) with XhoI restriction site (underlined). Finally, PCR products from the first two amplifications were extracted and used as templates for OE-PCR to obtained GDH-R3-LeuDH chimeric gene using Fusion-P1 and Fusion-P4. Then the obtained chimeric gene and pET-28a $(+)$ were digested with NdeI and XhoI and ligated together. The constructed plasmid was named pET-28a-GDH-R3-LeuDH and then transformed into $E$. coli BL21(DE3).

The gene of GDH and LeuDH was also performed PCR by corresponding primers. the GDH gene from pUC-GDH was amplified using GDH-P1 (5'-GGA ATTCCATATGTACAAAGATCTGGAAGGTAAAGT TGT-3') with NdeI restriction site (underlined) and GDH-P2 (5'-CCGCTCGAGTTAGCCACGGCCCGC CTGGAAGCTC-3') with XhoI restriction site (underlined). the LeuDH gene from pUC-LeuDH was amplified using LeuDH-P1 (5'-GGAATTCCATATGACATT GGAAATCTTCGAATATCTG-3') with NdeI restriction site (underlined) and LeuDH-P2 (5'-CCGCTCGAGTTA CCGGCGACTAATGATGT-3') with XhoI restriction site (underlined). The obtained gene and pET-28a $(+)$ 
were digested with NdeI and XhoI and ligated together. The constructed plasmids were named pET-28a-GDH and pET28a-LeuDH and then transformed into E. coli BL21 (DE3).

\section{Enzyme preparation and purification}

$200 \mathrm{~mL}$ of $\mathrm{LB}$ medium and $40 \mathrm{mg} / \mathrm{L}$ kanamycin were added in $1 \mathrm{~L}$ shake flask. The transformed E. coli BL21 (DE3) harboring fusion enzyme or free enzyme plasmids were cultured at $37^{\circ} \mathrm{C}, 200 \mathrm{rpm}$ in $1 \mathrm{~L}$ shaking flask. The expression of recombinant proteins was induced by the addition of $0.2 \mathrm{mM}$ isopropyl- $\beta$-D-thiogalactopyranoside (IPTG) when the optical density (OD600) was reached at $0.6-0.8$ and the E. coli was grown at $25^{\circ} \mathrm{C}$ for $16 \mathrm{~h}$. Cell was collected by centrifugation and then resuspended with PBS buffer. Cell was disrupted by ultrasonication and removed by centrifugation at $10,000 \mathrm{rpm}, 4^{\circ} \mathrm{C}$ for $20 \mathrm{~min}$. Obtained crude cell extract was then added to His-Trap column (His-Trap HP $5 \mathrm{~mL}$, GE Healthcare Corp., Piscataway, NJ, USA) which pre-equilibrated with binding buffer $(20 \mathrm{mM}$ sodium phosphate, $0.5 \mathrm{M} \mathrm{NaCl}, 20 \mathrm{mM}$ imidazole, $\mathrm{pH}$ 7.4). The binding buffer was equilibrated the column and eluting buffer $(20 \mathrm{mM}$ sodium phosphate, $0.5 \mathrm{M} \mathrm{NaCl}, 0.5 \mathrm{M}$ imidazole, $\mathrm{pH}$ 7.4) eluted at a gradient concentration. Target proteins were desalted and concentrated by Macrosep Advance Centrifugal Devices (cutoff $10 \mathrm{kDa}$, Pall, East Hills, NY, USA). The purity of the obtained enzymes was tested by $10 \%$ (w/v) SDS-PAGE. All the protein concentrations were determined using a modified Bradford Protein Assay Kit (Sangon Biotech Co. Ltd) with bovine serum albumin as standard.

\section{Enzyme characterization}

The Tecan M200 Pro plate reader (Tecan Group Ltd., Männedorf, Switzerland) was used to assay the activity of fusion enzyme, LeuDH and GDH by monitoring the $\mathrm{NADH}(\varepsilon=6.22 / \mathrm{mM} / \mathrm{cm})$ concentrations at $340 \mathrm{~nm}$ at $30{ }^{\circ} \mathrm{C}$. For the LeuDH part of fusion enzyme and LeuDH, the assay mixture contained $4.5 \mathrm{mM}$ trimethylpyruvic acid, $0.2 \mathrm{mM}$ NADH, $0.8 \mathrm{M} \mathrm{NH}_{4} \mathrm{Cl}_{-} \mathrm{NH}_{3} \cdot \mathrm{H}_{2} \mathrm{O}$ buffer $(\mathrm{pH}$ 10.0) and a certain amount of enzyme solution. For the $\mathrm{GDH}$ part of fusion enzyme and GDH, the assay mixture contained $20 \mathrm{mM}$ D-glucose, $2 \mathrm{mM} \mathrm{NAD}{ }^{+}$, PBS buffer $(\mathrm{pH}$ 7.4) and a certain amount of enzyme solution. The volume of the reaction mixture was $200 \mu \mathrm{L}$ in all cases. Reactions were initiated by the addition of NADH or $\mathrm{NAD}^{+}$. Enzyme activities were tested in triplicates. One unit of LeuDH and GDH activity was respectively defined as the amount of enzyme catalyzing the consumption or generation of $1 \mu \mathrm{mol}$ NADH per minute under standard measurement conditions. Protein concentration was assayed using the Modified Bradford Protein Assay Kit.

To study the effect of $\mathrm{pH}$ on fusion enzyme and free enzymes, enzyme activities were measured in buffers with different $\mathrm{pH}(0.2 \mathrm{M}$ potassium phosphate buffer including $\mathrm{NH}_{4}^{+}, \mathrm{pH}$ 6-8; $0.2 \mathrm{M} \mathrm{NH} \mathrm{NH}_{4} \mathrm{Cl}_{-} \mathrm{NH}_{3} \cdot \mathrm{H}_{2} \mathrm{O}$ buffer, $\mathrm{pH}$ 8-11). The effect of temperature on fusion enzyme and free enzymes were tested over the temperature range of $30-90{ }^{\circ} \mathrm{C}$. The activity was expressed as relative forms (\%) with the maximal value of enzyme activity at a certain $\mathrm{pH}$ or temperature as $100 \%$.

\section{Determination of thermal stability}

To determine the thermal stability of fusion enzyme and free enzymes, the purified fusion enzyme, GDH and LeuDH were pre-incubated at 40,50 and $60{ }^{\circ} \mathrm{C}$ water bath for $1 \mathrm{~h}$ and assayed for the residual GDH and LeuDH activity. The activity which was measured was calculated as a percentage of the original activities assayed before incubation. All measurements were performed in triplicate.

\section{Biocatalysis of L-tle and product analysis}

The standard reaction mixture contained $8 \mathrm{~g} / \mathrm{L}$ whole cells, $100 \mathrm{mM}$ trimethylpyruvic acid, $100 \mathrm{mM}$ D-glucose, $0.4 \mathrm{mM} \mathrm{NAD}{ }^{+}, \mathrm{pH} 9.0$ (adjusted by adding ammonia), followed by adding free enzyme mixture or fusion enzyme in a total reaction volume of $1 \mathrm{~mL}$. To study the effect of different conditions on the catalytic efficiency of fusion enzyme, different kinds and concentrations of cofactor and different concentrations of substrate and fusion enzyme were all examined. The reaction was performed at $30{ }^{\circ} \mathrm{C}$ with $200 \mathrm{rpm}$ of horizontal shaking if not specifically noted. Aliquots of the reaction mixture were taken and stored in $-80{ }^{\circ} \mathrm{C}$ for further analysis.

In order to obtain the concentration of L-tle after a reaction, HPLC was used to analyze the samples. The reaction samples were heat-denatured at $90{ }^{\circ} \mathrm{C}$ for $10 \mathrm{~min}$, firstly. Then precipitate protein was removed by centrifuging at $12,000 \times g$ for $10 \mathrm{~min}$. Finally, the supernatant samples were filtered using $0.22 \mu \mathrm{m}$ filter. The concentration and the optical purity (e.e. \%) of L-tle were determined at $35^{\circ} \mathrm{C}$ with HPLC column (Phenomenex Chirex 3126Dpenicillamine). The mobile phase was $2 \mathrm{mM}$ Copper (II) sulfate in water/isopropanol $(95: 5)$ at a flow rate of $0.8 \mathrm{~mL} / \mathrm{min}$.

\section{Supplementary Information}

The online version contains supplementary material available at https://doi. org/10.1186/s12934-020-01501-2.

Additional file 1. Figures and Table S1: The list of oligonucleotide primers. 


\section{Abbreviations}

GDH: Glucose dehydrogenase; LeuDH: Leucine dehydrogenase; TMA: Trimethylpyruvic acid; L-tle: L-tert-leucine.

\section{Acknowledgements}

This work was supported by the National Natural Science Foundation of China (Nos. 21978245 and 22008084), and the State Key Program of National Natural Science Foundation of China (No. 21336009).

\section{Authors' contributions}

$L L, Y W, R Q$ and SY performed the experiments; LL, YZ, YW, YF, AZ and BF analyzed the primary data; $\mathrm{LL}, \mathrm{YZ}$ and $\mathrm{BF}$ conceived and designed the project. BF supervised the project. All authors reviewed the manuscript. All authors read and approved the final manuscript.

\section{Funding}

This work was supported by the National Natural Science Foundation of China (Nos. 21978245 and 22008084), and the State Key Program of National Natural Science Foundation of China (No. 21336009).

\section{Availability of data and materials}

The datasets supporting the conclusions of this article are included within the article.

\section{Ethics approval and consent to participate \\ Not applicable.}

\section{Consent of publication}

Not applicable.

\section{Competing interests}

The authors declare that they have no competing interests.

\section{Author details}

${ }^{1}$ Department of Chemical and Biochemical Engineering, College of Chemistry and Chemical Engineering, Xiamen University, Xiamen 361005, People's Republic of China. ${ }^{2}$ College of Food and Biological Engineering, Jimei University, Xiamen, People's Republic of China. ${ }^{3}$ The Key Lab for Synthetic Biotechnology of Xiamen City, Xiamen University, Xiamen, Fujian, People's Republic of China.

Received: 20 Auqust 2020 Accepted: 23 December 2020 Published online: 06 January 2021

\section{References}

1. Luo W, Zhu J, Zhao Y, Zhang H, Yang X, Liu Y, Rao Z, Yu X. Cloning and expression of a novel leucine dehydrogenase: characterization and L-tertLeucine production. Front Bioeng Biotech. 2020;8:186.

2. Jiang W, Fang B. Synthesizing Chiral Drug Intermediates by Biocatalysis. Appl Biochem Biotech. 2020;192:146-79.

3. Jin JZ, Chang DL, Zhang J. Discovery and Application of New Bacterial Strains for Asymmetric Synthesis of L-Tert-Butyl Leucine in High Enantioselectivity. Appl Biochem Biotech. 2011;164:376-85.

4. Liu W, Ma H, Luo J, Shen W, Xu X, Li S, Hu Y, Huang H. Efficient synthesis of L-tert-leucine through reductive amination using leucine dehydrogenase and formate dehydrogenase coexpressed in recombinant E. coli. Biochem Eng J. 2014;91:204-9.

5. Kragl U, Vasic-Racki D, Wandrey C. Continuous production of L-tert-leucine in series of two enzyme membrane reactors: modelling and computer simulation. Bioprocess Eng. 1996;14:291-7.

6. Hong E, Cha M, Yun H, Kim B. Asymmetric synthesis of L-tert-leucine and 1-3-hydroxyadamantylglycine using branched chain aminotransferase. J Mol Catal B-Enzym. 2010;66:228-33.

7. Stelkes-Ritter U, Beckers G, Bommarius A, Drauz K, Günther K, Kottenhahn M, Schwarm M, Kula MR. Kinetics of peptide amidase and its application for the resolution of racemates. Biocatal Biotransfor. 1997;15:205-19.

8. Agosta E, Caligiuri A, D'Arrigo P, Servi S, Tessaro D, Canevotti R. Enzymatic approach to both enantiomers of $\mathrm{N}$-Boc hydrophobic amino acids. Tetrahedron-Asymmetr. 2006;17:1995-9.
9. Liu W, Luo J, Zhuang X, Shen W, Zhang Y, Li S, Hu Y, Hu Y. Efficient preparation of enantiopure L-tert-leucine through immobilized penicillin $\mathrm{G}$ acylase catalyzed kinetic resolution in aqueous medium. Biochem Eng J. 2014;83:116-20.

10. Turner NJ, Winterman JR, McCague R, Parratt J, Taylor S. Synthesis of homochiral L-(S)-tert-leucine via a lipase catalysed dynamic resolution process. Tetrahedron Lett. 1995;36:1113-6.

11. Bommarius AS, Schwarm M, Drauz K. Biocatalysis to amino acid-based chiral pharmaceuticals_examples and perspectives. J Mol Catal B-Enzym. 1998;5:1-11.

12. Menzel A, Werner H, Altenbuchner J, Gröger H. From enzymes to "designer bugs" in reductive amination: a new process for the synthesis of L-tert-leucine using a whole cell-catalyst. Eng Life Sci. 2004;4:573-6.

13. Li J, Pan J, Zhang J, Xu JH. Stereoselective synthesis of L-tert-leucine by a newly cloned leucine dehydrogenase from Exiguobacterium sibiricum. J Mol Catal B-Enzym. 2014;105:11-7.

14. Liese A, Seelbach K, Wandrey C. Industrial Biotransformations. 2nd ed. Weinheim: Wiley-VCH; 2006.

15. Dunn MF, Niks D, Ngo H, Barends TR, Schlichting I. Tryptophan synthase: the workings of a channeling nanomachine. Trends Biochem Sci. 2008;33:254-64.

16. Hyeon JE, Jeon SD, Han SO. Cellulosome-based, Clostridium-derived multi-functional enzyme complexes for advanced biotechnology tool development: advances and applications. Biotechnol Adv. 2013;31:936-44

17. Hirakawa H, Haga T, Nagamune T. Artificial protein complexes for biocatalysis. Top Catal. 2012;55:1124-37.

18. Gao X, Yang S, Zhao C, Ren Y, Wei D. Artificial Multienzyme supramolecular device: highly ordered self-assembly of oligomeric enzymes in vitro and in vivo. Angew Chem Int Edit. 2014;53:14027-30.

19. Zhang $Y$, Wang $Y$, Wang $S$, Fang B. Engineering bifunctional enzyme complex of formate dehydrogenase and leucine dehydrogenase by peptide linker mediated fusion for accelerating cofactor regeneration. Eng Life Sci. 2017;17:989-96.

20. Zhang YHP. Substrate channeling and enzyme complexes for biotechnological applications. Biotechnol Adv. 2011;29:715-25.

21. Zhuang X, Zhang A, Qiu S, Tang C, Zhao S, Li H, Zhang Y, Wang Y, Wang B, Fang B, Hong W. Coenzyme coupling boosts charge transport through single bioactive enzyme junctions. iScience. 2020;23:101001.

22. Yang $X, M u X, N i e Y, X u Y$. High efficient co-expression of leucine dehydrogenase and glucose dehydrogenase in Escherichia coli. Acta Microbiologica Sinica. 2016;56:1709-18.

23. Liechti G, Singh R, Rossi PL, Gray MD, Adams NE, Maurell AT. Chlamydia trachomatis dapF encodes a bifunctional enzyme capable of both D-glutamate racemase and diaminopimelate epimerase Activities. Mbio. 2018;9:e00204-18.

24. Böttcher T. From molecules to life: quantifying the complexity of chemical and biological systems in the Universe. J Mol Evol. 2018;86:1-10.

25. Wichmann R, Vasic-Racki D. Cofactor regeneration at the lab scale. Adv biochem Eng Biot. 2005;92:225-60.

26. Conrado RJ, Varner JD, DeLisa MP. Engineering the spatial organization of metabolic enzymes: mimicking nature's synergy. Curr Opin Biotech. 2008;19:492-9.

27. Lu P, Feng MG. Bifunctional enhancement of a $\beta$-glucanase-xylanase fusion enzyme by optimization of peptide linkers. Appl Microbiol Biot. 2008;79:579-87.

28. Huang Z, Ye F, Zhang C, Chen S, Chen Y, Wu J, Togo M, Xing X. Rational design of a tripartite fusion protein of heparinase I enables one-step affinity purification and real-time activity detection. J Biotechnol. 2013;163:30-7.

29. Wang S, Cui GZ, Song XF, Feng Y, Cui Q. Efficiency and stability enhancement of Cis-epoxysuccinic acid hydrolase by fusion with a carbohydrate binding module and immobilization onto cellulose. Appl Biochem Biotech. 2012;168:708-17.

30. Bülow L. Preparation of artificial bifunctional enzymes by gene fusion. Biochem Soc Symp. 1990;57:123-33.

31. Hölsch K, Weuster-Botz D. Enantioselective reduction of prochiral ketones by engineered bifunctional fusion proteins. Biotechnol Appl Bioc. 2010;56:131-40.

32. Fu J, Yang YR, Johnson-Buck A, Liu M, Liu Y, Walter NG, Woodbury NW, Yan H. Multi-enzyme complexes on DNA scaffolds capable of 
substrate channelling with an artificial swinging arm. Nat Nanotechnol. 2014:9:531-6.

33. Aevarsson A, Seger K, Turley S, Sokatch JR, Hol WG. Crystal structure of 2-oxoisovalerate and dehydrogenase and the architecture of 2-oxo acid dehydrogenase multienzyme complexes. Nat Struct Biol. 1999;6:785-92.

34. Grogan G. Synthesis of chiral amines using redox biocatalysis. Curr Opin Chem Biol. 2018;43:15-22.

35. Kurbanoglu EB, Zilbeyaz K, Taskin M, Kurbanoglu NI. Total production of (R)-3,5-bistrifluoromethylphenyl ethanol by asymmetric reduction of 3,5-bis(trifluoromethyl)-acetophenone in the submerged culture of Penicillium expansum isolate. Tetrahedron-Asymmetr. 2009;20:2759-63.

36. Lu J, Zhang Y, Sun D, Jiang W, Wang S, Fang B. The development of leucine dehydrogenase and formate dehydrogenase bifunctional enzyme cascade improves the Biosynthsis of L-tert-Leucine. Appl Biochem Biotech. 2016;180:1180-95.

37. Arnold K, Bordoli L, Kopp J, Schwede T. The SWISS-MODEL workspace: a web-based environment for protein structure homology modelling. Bioinformatics. 2006;22:195-201.

\section{Publisher's Note}

Springer Nature remains neutral with regard to jurisdictional claims in published maps and institutional affiliations.
Ready to submit your research? Choose BMC and benefit from:

- fast, convenient online submission

- thorough peer review by experienced researchers in your field

- rapid publication on acceptance

- support for research data, including large and complex data types

- gold Open Access which fosters wider collaboration and increased citations

- maximum visibility for your research: over $100 \mathrm{M}$ website views per year

At BMC, research is always in progress.

Learn more biomedcentral.com/submissions 